\title{
Age, Race and Gender Spatiotemporal Disparities of COPD Emergency Room Visits in Houston, Texas
}

\author{
Faye Anderson, Arch Carson, Lawrence Whitehead, Keith Burau \\ Texas A \& M AgriLIFE Research Center, Beaumont, Texas, USA \\ Email: andersonfaye7@gmail.com
}

Received 12 January 2015; accepted 26 January 2015; published 4 February 2015

Copyright (C) 2015 by authors and Scientific Research Publishing Inc.

This work is licensed under the Creative Commons Attribution International License (CC BY). http://creativecommons.org/licenses/by/4.0/

(c) (i) Open Access

\section{Abstract}

Chronic obstructive pulmonary disease (COPD) is one of the major causes of morbidity and mortality in the United State. The investigation of the continuing increase in its prevalence and mortality has increased attempts to further understand its causes and how to manage it. Understanding the spatial and temporal distribution of COPD emergency room (ER) visits in Harris County (Houston) can guide these efforts in a uniform yet diverse setting like this one. The objectives of this study were to identify the temporal and spatial variations of COPD emergency room visits adjusted by age, gender, ethnicity, day of the week, month, and year, and to estimate the odds ratio of COPD emergency room visits adjusted by the six risk factors. The dataset used were extracted from two resources: ER Utilization Study and Harris County centroid coordinates. Exploratory statistical analyses were conducted to study the spatiotemporal disparities and investigate associations. Logistic regression was performed to estimate the odds ratio of COPD primary diagnosis adjusted for age, race, gender, day of the week, month, and year. The number of COPD ER visits kept increasing from 2004 throughout 2009 but there was a significant increase after the year 2005. Spring and summer had lower visits compared to winter and autumn. Lowest visits were during June and July and higher during December and January. Tuesdays had the highest number of visits compared to the remaining days of the week with Saturdays having had the lowest number of visits. Temporal analyses show the continuous increase in COPD ER visits in Houston as well as the consistent spatial disparities between zip regions. After adjustment for age, race, gender, day of the week, month, and year, there were statistically significant associations between emergency room chronic obstructive pulmonary disease diagnoses in Houston, Texas, with these six predictors.

\section{Keywords}

COPD, Houston Texas, Ozone, Particulate Matter, Logistic Regression 


\section{Introduction}

COPD refers to progressive lung diseases that block airflow during exhalation making it difficult to breathe. COPD causes include passive and active smoking, occupational exposures, air pollutants, genetics, autoimmune disease and other risk factors. COPD includes chronic bronchitis, emphysema, bronchiectasis, and chronic airway obstruction [1] [2]. COPD is the fourth leading cause of death in the US with a death rate in 2006 of 46.4 per 100,000, causing about 126,005 US deaths in people older than 25 [3]. Gender, race and age differences are seen in the prevalence of [4]. The estimated average cost of an ER visit in Harris County for 2009 was four times that of the national average (\$800 versus $\$ 200$, respectively). The number of COPD ER visits for 2009 were highest than those for the earlier five years. The ER visit rate of Harris county residents was about 32.84 per 1000 residents in 2009, exceeding the 30.91 and 30.0 ER visit rates in 2007 and 2008 respectively [5]. Despite the extensive research on COPD and its association with air pollution, key questions remain unanswered in the literature regarding the Houston region, including: 1) where are the most high risk zip code regions in Harris County (Houston) for COPD? 2) What is the spatial disparity for COPD ER visits adjusted by age, sex and race? And 3) what is the temporal distribution for COPD ER visits adjusted by age, sex and race? This study presents a methodological approach to answer these enquiries.

\section{Methods}

Data was obtained from two sources. The first dataset has Harris County daily emergency room visits for COPD from 2004 through 2009. This dataset was developed by Dr. Charles Begley (ER Utilization Study), University of Texas School of Public Health. This includes ER visits for six years from hospitals that serve the general public of Harris County [5]. COPD ER visits are those with a primary diagnosis of chronic obstructive pulmonary disease (COPD) including chronic bronchitis (ICD-9 codes 490 - 491), emphysema (ICD-9 code 492), asthma (ICD-9 code 493), bronchiectasis (ICD-9 code 494), and chronic airway obstruction (ICD-9 code 496) [1] [6]. Population estimates of 2004 were the same as 2000 census counts. Years 2005 through 2009 population estimates were provided to the ER Utilization Study by Environmental Systems Research Institute, Inc. [7]. The second dataset is the centroid coordinates for Harris County zip codes from Texas State Data Center (TSDC) website http://txsdc.utsa.edu/txdata/shapefiles/.

After conducting exploratory statistical analyses, logistic regressions were conducted. The choice of the regression best suits the nature of the outcomes and predictors-logistic regression measures the association between dichotomous dependent variable (COPD ER visits) and the independent variables. The logistic model assumes that the logit of the probability for COPD ER visits is a linear function of the independent variables age, gender, ethnicity, day of the week, month, and year. The logit of a probability $P$ is defined as $\log (p / 1-p)$, where $\log$ represents the natural logarithm [8] [9]. The logistic prediction equation will be: $\operatorname{logit}[\mathrm{P}(\mathrm{COPD}=1)]=$ intercept + B1 $\times$ age + B2 $\times$ race + B3 $\times$ gender + B4 $\times$ day of the week + B5 $\times$ month + B6 $\times$ year. Logistic regressions were conducted for the bivariate associations between COPD diagnosis and the six independent variables and for the multivariate associations. Significance levels used were 0.05 .

\section{Results}

\subsection{Temporal Disparities}

Incidence proportions for COPD cases increased from 2004 to 2009 by a factor four respectively (Figure 1). This is a serious epidemiological finding especially when compared to national prevalence of the two outcomes for the same years [10]. There are many plausible explanations for this many-fold increase in COPD ER visits diagnoses during the six years. Including but not limited to socioeconomic reasons. According to data released by the United States Census Bureau on June 14, 2006, Houston's Harris County received 92,824 immigrants as a result of Hurricane Rita and Hurricane Katrina, immediately prior to and following the hurricanes. However, higher estimates of immigrates have settled in Harris County, approximately one million during 18 month period following the hurricanes. Most of them were African Americans who did not have jobs, or lost their homes because of the hurricanes [11]. This (economic status) makes their choice to seek medical care at ERs expected.

The total number of ER visits included is more than 3.7 million visits representing six years and the one hundred forty one zip codes of Harris County. Mean annual COPD ER visit diagnosis incidence proportion ranged from 146 to 523 cases per 100,000 populations. Annual and monthly incidence proportions for COPD ER visits 


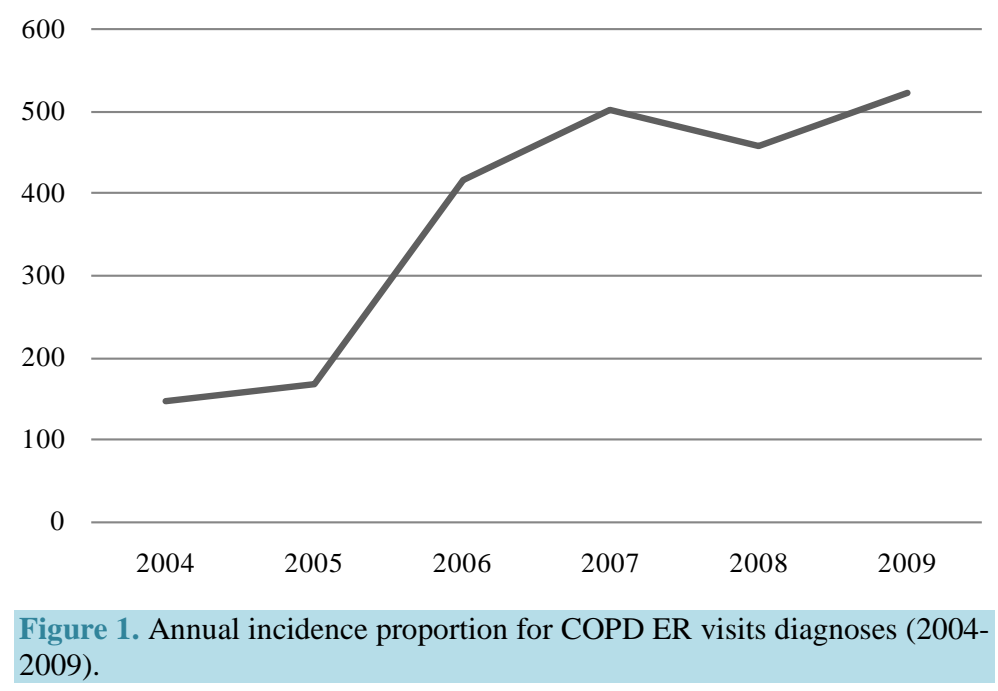

diagnoses were lowest for 2004 and kept increasing to reach its highest in 2009 (Figure 2). The seasonal pattern for the incidence proportion of COPD diagnosis stayed the same during the six years: lowest during spring and summer and highest during winter and autumn (Figure 2). Monthly incidence proportion for COPD ER visits had a consistent pattern for the six years: lowest during June or July and highest during January and December (Figure 3 and Figure 4). The lowest percentage of COPD cases was for aging patients. Temporal variation between the seven days of the week show that the percentages more than doubled after the year 2005, and that Tuesdays had the highest number of visits whereas Saturdays had the least percentages. The percentage of ER visits for every day of the week ranged from fourteen to fifteen percent of total visits. Thirty two percent of the visits were for Whites, twenty nine percent for blacks, thirty two for Hispanics, and seven percent for the remaining ethnicities. Forty four percent of COPD ER visits were for males. The mean age was about 32 years (24 years standard deviation) (Table 1).

\subsection{Spatial Disparities}

Figure 5 present unadjusted incidence proportions (IP) for COPD ER visit diagnosis. The distribution of COPD ER visits incidence proportion remained almost unchanged from 2004 to 2009. A higher clustering of cases showed in a few zip regions: 77,050, which is to the east of Highway 59 and inside northeast Beltway 8; 77,547, which is south of Interstate 10 and east of Interstate 610 east; 77,094, which is to the south of Highway 59 and at the southwestern part of the County; and the fourth zip region of high incidence proportion is 77,085 , which is at the most southwestern point inside BW8. The three zip regions 77,050, 77,085, and 77,094 had the highest incidence proportions for COPD diagnosis.

\subsection{Logistic Regression Models}

Estimates from unadjusted logistic regressions show that there is a statistically significant association between COPD ER visits and blacks ( $\mathrm{OR}=1.298713,95 \% \mathrm{CI}=1.279947-1.317755, \mathrm{p}<0.001)$, males $(\mathrm{OR}=1.149738$, $95 \% \mathrm{CI}=1.135971-1.163672$, $\mathrm{p}$ value $<0.001)$, December $(\mathrm{OR}=1.066658,95 \% \mathrm{CI}=1.039403-1.094628, \mathrm{p}$ value $<0.001$ ), and each of the years (Table 1 ). As for the adjusted logistic regression, there is a significant association of emergency room COPD diagnosis in Harris County, Texas, with the same factors: blacks, males, December and each of the years (Table 2).

\section{Discussion}

The data related to COPD cases establishes that more cases occur during the winter months, with fewer during the summer. During the winter months, home occupants keep natural ventilation, windows and doors, closed to minimize cold air circulation into the home in an effort to minimize energy costs. Therefore, outdoor air cannot enter the home and dilute contaminants that may be in the air. For example, adding insulation and caulking to 


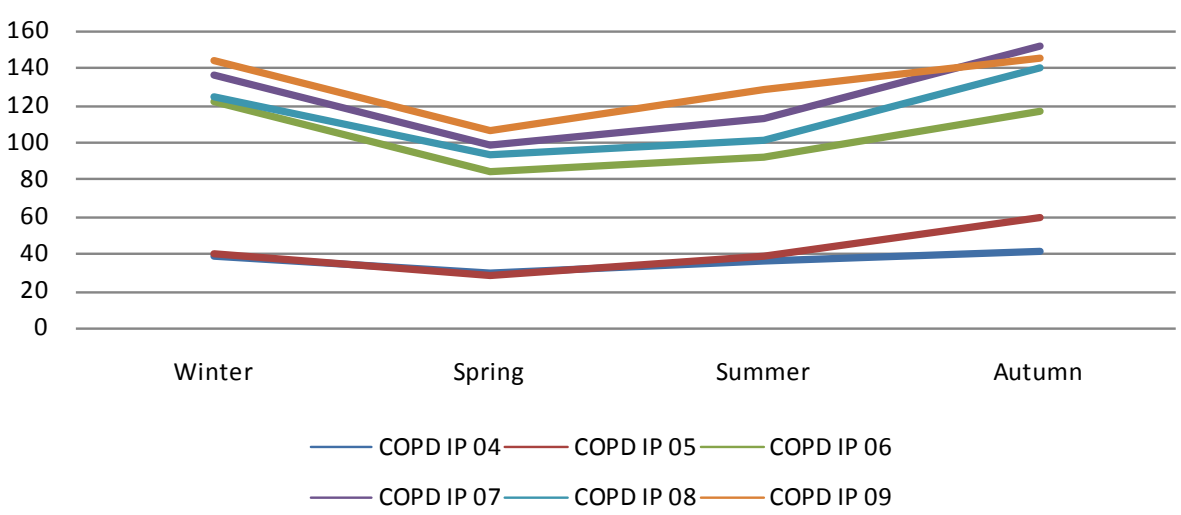

Figure 2. COPD ER visits diagnoses seasonal incidence proportion-overlapped (20042009).

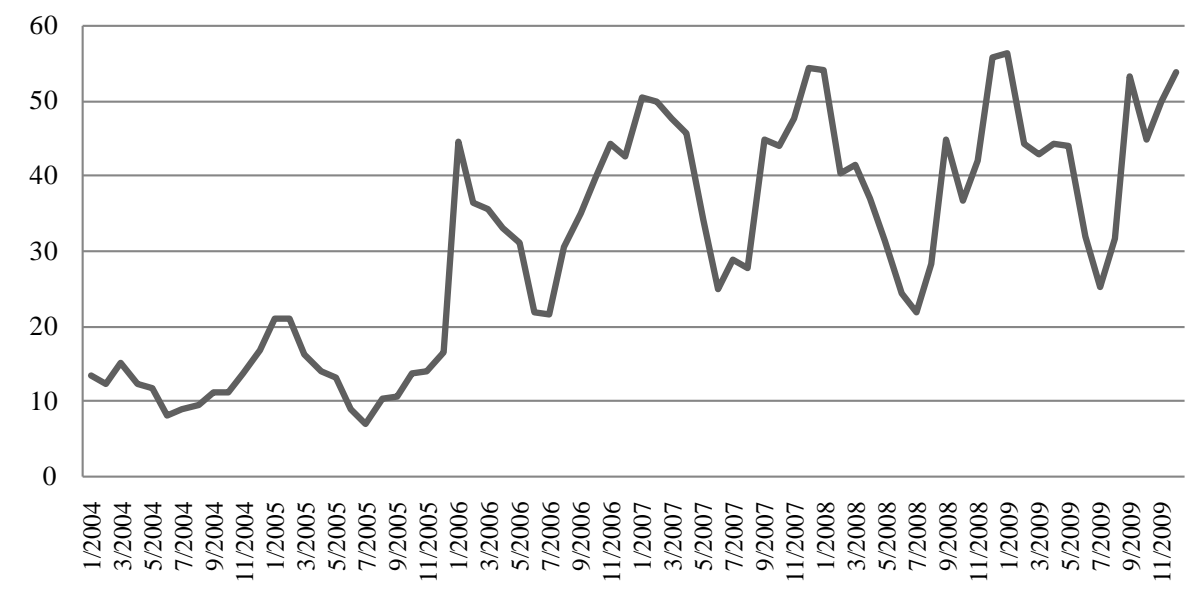

Figure 3. Monthly incidence proportions for COPD cases—sequential (2004-2009).

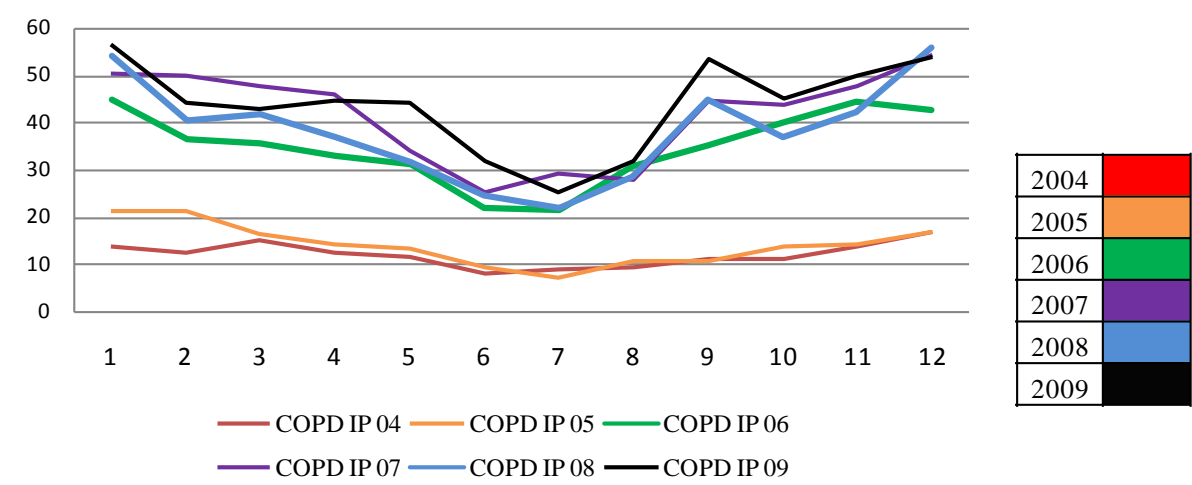

Figure 4. Monthly incidence proportions for COPD cases—overlapped (2004-2009).

weatherize the home can reduce air circulation and trap contaminants inside the home. Indoor air pollution studies have identified several contaminants that can be present in indoor air, and is usually caused by the accumulation of contaminants from various sources inside the home. This includes fireplaces, stoves, cigarettes, cleaning products, newer building materials, and chemical stored in the home can cause indoor air problems. Occupants of homes with poor indoor air quality may have symptoms such as headache, eye irritation, fatigue, sinus congestion, dizziness and nausea. COPD trends increase due to PM2.5 exposure in the home [10]. COPD rates during the winter months have been well researched and documented showing consistent trends. COPD exacer- 


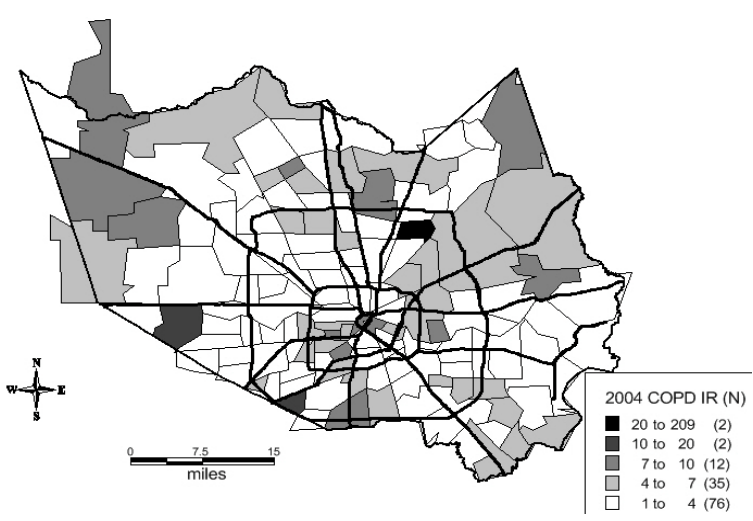

(a)

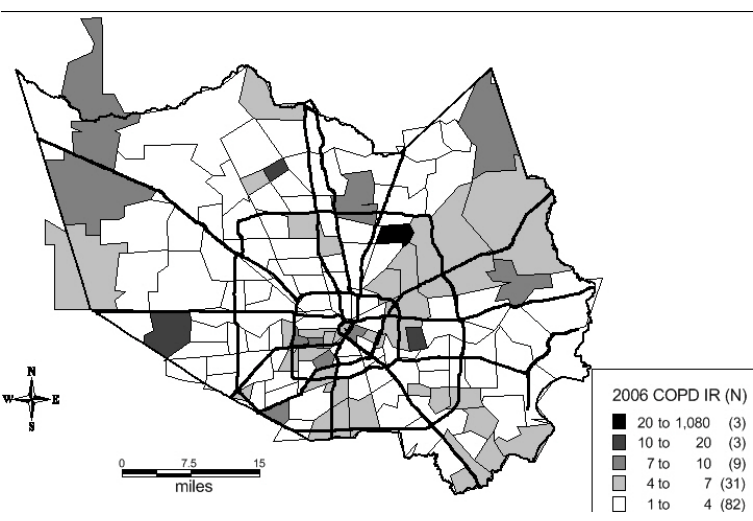

(c)

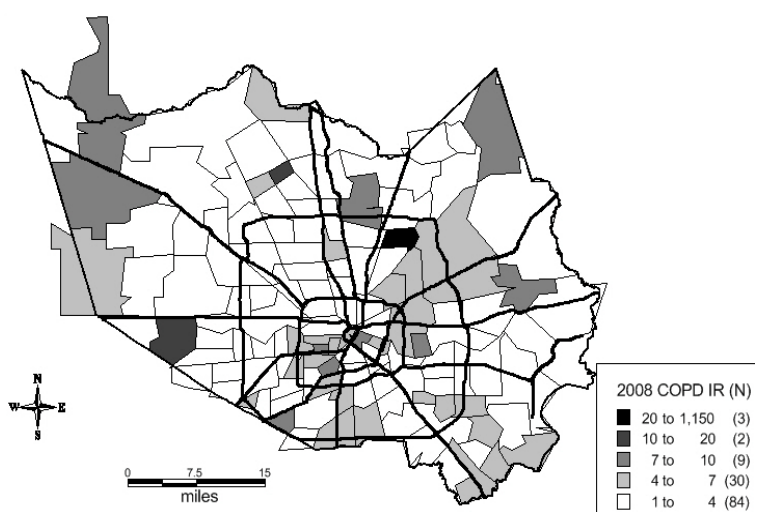

(e)

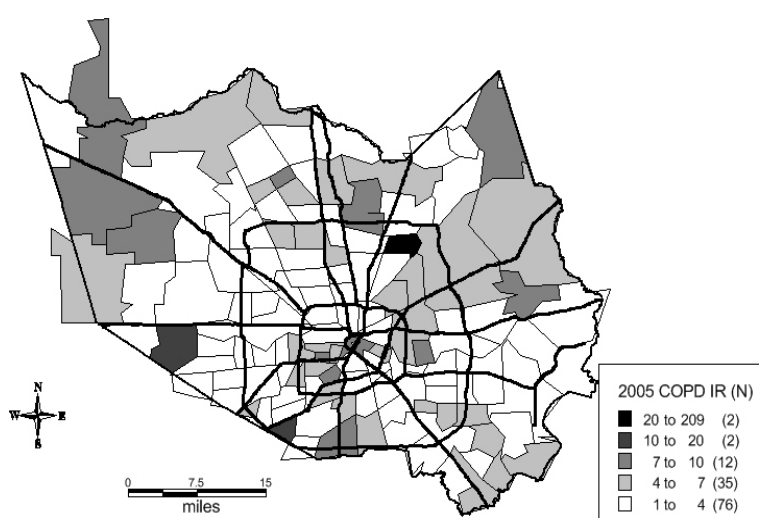

(b)

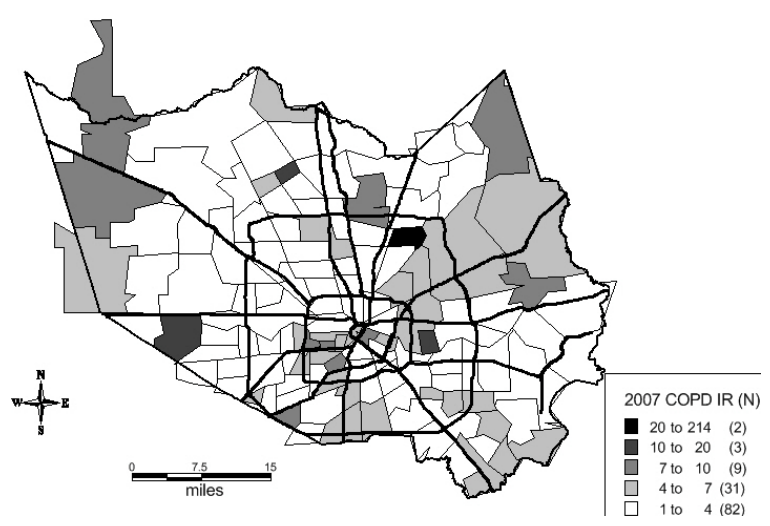

(d)

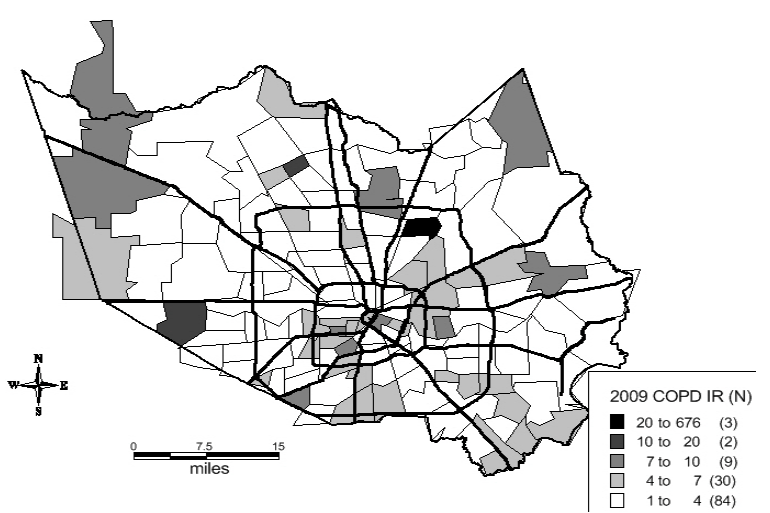

(f)

Figure 5. IPs for COPD ER Visits in Harris County (2004-2009). (a) COPD IPs for 16 hospitals with overall county coverage of 50\% of ER visits in 2004; (b) COPD IPs for 25 hospitals with overall county coverage of $69 \%$ of ER visits in 2005; (c) COPD IPs for 25 hospitals with overall county coverage of 50\% of ER visits in 2006; (d) COPD IPs for 25 hospitals with overall county coverage of 50\% of ER visits in 2007; (e) COPD IPs for 25 hospitals with overall county coverage of 50\% of ER visits in 2008; (f) COPD IPs for 24 hospitals with overall county coverage of $50 \%$ of ER visits in 2009. The top range is from 20 to the maximum incidence proportion for each year. Maximum IP changes by year.

bations, which are a major cause of morbidity and mortality, are associated with higher hospital admissions during periods of cold weather [12]-[15]. This is another possible explanation of higher winter incidence proportions.

The results of the adjusted logistic model for COPD cases show that the odds for COPD in December were 5\% higher than the odds for January, for the year 2005 the odds for COPD were 9\% higher than in 2004, for the year 2006 the odds for COPD were 21\% higher than in 2004, for the year 2007 the odds for COPD were 260\% higher 
Table 1. Estimated unadjusted odds ratio of COPD ER visit diagnosis by risk factors.

\begin{tabular}{|c|c|c|c|c|c|}
\hline Variable $(\mathrm{N}=3,742,090)$ & Mean (SD) & OR & P Value & \multicolumn{2}{|c|}{$95 \% \mathrm{CI}$} \\
\hline Age (Years) & $32.23(24)$ & 0.9987559 & 0.00 & 0.99900798 & 0.99850383 \\
\hline Race (Ref = White) & $32 \%$ & 1.00 & & & \\
\hline Hispanic & $32 \%$ & 0.819229 & 0.00 & 0.80625 & 0.832417 \\
\hline Black & $29 \%$ & 1.298713 & 0.00 & 1.279947 & 1.317755 \\
\hline Other & $7 \%$ & 0.8130546 & 0.00 & 0.7906744 & 0.8360682 \\
\hline Gender $($ Ref $=$ Female $)$ & $56 \%$ & 1.00 & & & \\
\hline Male & $44 \%$ & 1.149738 & 0.00 & 1.135971 & 1.163672 \\
\hline Day of the Week (Ref = Sun) & $15 \%$ & 1.00 & & & \\
\hline Mon & $15 \%$ & 0.9676588 & 0.00 & 0.9471832 & 0.9885769 \\
\hline Tue & $14 \%$ & 0.926117 & 0.00 & 0.9060554 & 0.9466228 \\
\hline Wed & $14 \%$ & 0.9094932 & 0.00 & 0.889578 & 0.9298543 \\
\hline Thu & $14 \%$ & 0.8871639 & 0.00 & 0.8675031 & 0.9072702 \\
\hline Fri & $14 \%$ & 0.8621447 & 0.00 & 0.8429226 & 0.8818052 \\
\hline Sat & $14 \%$ & 0.9030775 & 0.00 & 0.8833774 & 0.9232169 \\
\hline Month $($ Ref $=$ Jan $)$ & $9 \%$ & 1.00 & & & \\
\hline Feb & $8 \%$ & 0.9253533 & 0.00 & 0.9007364 & 0.950643 \\
\hline Mar & $9 \%$ & 0.8371316 & 0.00 & 0.8146833 & 0.8601985 \\
\hline Apr & $8 \%$ & 0.8059881 & 0.00 & 0.7840069 & 0.8285857 \\
\hline May & $9 \%$ & 0.6973015 & 0.00 & 0.6777223 & 0.7174463 \\
\hline Jun & $8 \%$ & 0.5456069 & 0.00 & 0.5287041 & 0.5630501 \\
\hline Jul & $8 \%$ & 0.5050981 & 0.00 & 0.4891238 & 0.521594 \\
\hline Aug & $8 \%$ & 0.606915 & 0.00 & 0.5888086 & 0.6255782 \\
\hline Sep & $8 \%$ & 0.8543239 & 0.00 & 0.8314514 & 0.8778256 \\
\hline Oct & $8 \%$ & 0.8128291 & 0.00 & 0.7907389 & 0.8355364 \\
\hline Nov & $8 \%$ & 0.9503492 & 0.00 & 0.9252994 & 0.9760771 \\
\hline Dec & $8 \%$ & 1.066658 & 0.00 & 1.039403 & 1.094628 \\
\hline Year $($ Ref $=2004)$ & $8 \%$ & 1.00 & & & \\
\hline 2005 & $8 \%$ & 1.097846 & 0.00 & 1.062822 & 1.134025 \\
\hline 2006 & $20 \%$ & 1.218226 & 0.00 & 1.185538 & 1.251815 \\
\hline 2007 & $12 \%$ & 2.607775 & 0.00 & 2.539152 & 2.678252 \\
\hline 2008 & $25 \%$ & 1.082041 & 0.00 & 1.053424 & 1.111436 \\
\hline 2009 & $27 \%$ & 1.159948 & 0.00 & 1.129699 & 1.191007 \\
\hline
\end{tabular}


Table 2. Estimated odds ratio of COPD ER visit diagnosis adjusted by risk factors.

\begin{tabular}{|c|c|c|c|c|c|}
\hline Variable $(\mathrm{N}=3,742,090)$ & Mean (SD) & OR & P Value & \multicolumn{2}{|c|}{$95 \% \mathrm{CI}$} \\
\hline Age (Years) & $32.23(24)$ & 0.9979873 & 0.00 & 0.9977255 & 0.9982491 \\
\hline Race (Ref = White) & $32 \%$ & 1.00 & & & \\
\hline Hispanic & $32 \%$ & 0.7828379 & 0.00 & 0.769971 & 0.7959199 \\
\hline Black & $29 \%$ & 1.270946 & 0.00 & 1.252308 & 1.289862 \\
\hline Other & $7 \%$ & 0.7847539 & 0.00 & 0.7630033 & 0.8071246 \\
\hline Gender $($ Ref = Female $)$ & $56 \%$ & 1.00 & & & \\
\hline Male & $44 \%$ & 1.172541 & 0.00 & 1.158398 & 1.186856 \\
\hline Day of the Week $($ Ref $=$ Mon) & $15 \%$ & & & & \\
\hline Tue & $15 \%$ & 0.9614789 & 0.00 & 0.9410557 & 0.9823453 \\
\hline Wed & $14 \%$ & 0.918849 & 0.00 & 0.8988675 & 0.9392747 \\
\hline Thu & $14 \%$ & 0.9022155 & 0.00 & 0.8823848 & 0.922492 \\
\hline Fri & $14 \%$ & 0.8840275 & 0.00 & 0.8643642 & 0.9041382 \\
\hline Sat & $14 \%$ & 0.8627055 & 0.00 & 0.8434007 & 0.8824521 \\
\hline Sun & $14 \%$ & 0.9059972 & 0.00 & 0.8861664 & 0.9262716 \\
\hline Month (Ref = Jan) & $9 \%$ & 1.00 & & & \\
\hline Feb & $8 \%$ & 0.9168744 & 0.00 & 0.8924079 & 0.9420117 \\
\hline Mar & $9 \%$ & 0.8325254 & 0.00 & 0.8101365 & 0.8555331 \\
\hline Apr & $8 \%$ & 0.8122498 & 0.00 & 0.7900357 & 0.8350885 \\
\hline May & $9 \%$ & 0.7087196 & 0.00 & 0.6887683 & 0.729249 \\
\hline Jun & $8 \%$ & 0.5534716 & 0.00 & 0.5362854 & 0.5712086 \\
\hline Jul & $8 \%$ & 0.5096805 & 0.00 & 0.4935233 & 0.5263667 \\
\hline Aug & $8 \%$ & 0.6116166 & 0.00 & 0.5933232 & 0.6304741 \\
\hline Sep & $8 \%$ & 0.8559826 & 0.00 & 0.8329931 & 0.8796066 \\
\hline Oct & $8 \%$ & 0.8094249 & 0.00 & 0.7873628 & 0.8321052 \\
\hline Nov & $8 \%$ & 0.9395736 & 0.00 & 0.9147279 & 0.9650942 \\
\hline Dec & $8 \%$ & 1.055295 & 0.00 & 1.028237 & 1.083064 \\
\hline Year $($ Ref $=2004)$ & $8 \%$ & & & & \\
\hline 2005 & $8 \%$ & 1.093982 & 0.00 & 1.059027 & 1.13009 \\
\hline 2006 & $20 \%$ & 1.218555 & 0.00 & 1.185814 & 1.252201 \\
\hline 2007 & $12 \%$ & 2.607205 & 0.00 & 2.538424 & 2.677849 \\
\hline 2008 & $25 \%$ & 1.088953 & 0.00 & 1.060098 & 1.118594 \\
\hline 2009 & $27 \%$ & 1.174778 & 0.00 & 1.144088 & 1.206291 \\
\hline
\end{tabular}

than in 2004, for the year 2008 the odds for COPD were 8\% higher than in 2004, for the year 2009 the odds for COPD were $17 \%$ higher than in 2004, the visits' odds for blacks were $27 \%$ higher than the odds for whites, and the odds for males were $17 \%$ higher than females. Men are more likely to smoke than women, and black men are more likely to smoke cigarettes than white men [16]. This can explain the higher odds for COPD cases for 
blacks and/or men. COPD disease may be influenced by race, ethnicity, gender and genetic inheritances. Limited data exists that compares COPD in different racial or ethnic groups. However this data suggests that differences may exist. Potential differences between racial or ethnic groups may include biological differences as well as disparities in diagnosis and treatment. It may also include lack of enrollment of minorities in epidemiological trials [17] [18].

Comparing the spatial distribution of family median income to those of the dominant distributions for COPD cases, it can be concluded that the relationship between median income and the number of cases of COPD is not straightforward. The spatial distribution is somewhat inversed when comparing the western and east-central parts of the County. Higher income correlated to fewer cases in the western part of the country, and lower income correlated to fewer cases in the east-central part of the country. This analysis will require more investigation in the future.

\section{Strengths and Limitations}

This is the first study to explore spatial and temporal trends for COPD emergency room visits over multiple years and for all ages of patients in Harris County, Texas. This study covers many of the missing pieces, for example including up to twenty sequential seasons. In 2009, 1,127,557 ER visits were made to all twenty four participating hospitals. Of this total, $84.8 \%$ were made by Harris County residents. The ER visits of participating hospitals are $74.04 \%$ of all ER visits reported to the Texas Department of State Health Services by all hospitals in Harris County in 2009 [5]. The large size of the database and hence the high statistical power of the analysis allows for the investigation of variances of predictors and the outcome (COPD). Furthermore, the data span of six years provides enough variance to study the daily, weekly, monthly and seasonal effects of exposure. One of this study's limitations is the possible existence of bias from misclassifying primary diagnoses due to data entry or other errors. Moreover, the dataset did not contain possible confounders like smoking, life style, and individual exposure to air pollutants.

\section{Conclusions}

The study dataset contained daily emergency room visits for Harris County, Texas, from 2004 to 2009 along with each patient's age, race, gender, day of the week, month, and year. The dichotomous outcome was emergency room visits diagnoses for chronic obstructive pulmonary disease. Spatial and temporal disparities were investigated. Logistic regressions were conducted to estimate odds ratios of the outcome. The dataset included all ER visits surveyed by Safety Net from 2004 to 2009. There were 95,765 COPD cases during this six year period. Being black was associated with $27 \%$ increase in the odds of chronic obstructive pulmonary disease emergency room diagnoses, being a male was associated with a 17\% increase in the odds of COPD ER visit diagnosis, visits in December had a 5\% increase in the odds, and each of the 2004 following years had a higher odds of COPD ER visit preliminary diagnosis. With all of the increases in the odds combined, the outcome translates to more emergency room visits per year, with higher costs per year.

This study points to other potential factors that contribute to the rising incidence proportions of COPD in Harris County such as patient history, life style, and other pollutants. COPD is of the most important causes of morbidity and mortality in the United States. Continuing increases in COPD prevalence and mortality should be anticipated in the coming decades. Therefore, a concerted nationwide effort for increasing awareness COPD should be called for by an organization such as the CDC or perhaps the WHO. With the attempt to increase the awareness of the huge burden of respiratory diseases among the public and the policy makers, comprehensive figures on the mortality, morbidity and costs of COPD should be published. Additionally, new opportunities for research on COPD could be realized with the increased public awareness and opinion, which should help to alleviate the suffering of millions of citizens in the United States and perhaps across the world.

\section{Acknowledgements}

Special thanks go to Dr. Charles Begley for providing the data, and to Patrick Courtney for his technical support.

\section{References}

[1] CDC (1998) Chronic Obstructive Pulmonary Disease. http://www.cdc.gov/niosh/pdfs/98-157-d.pdf 
[2] NHLBI (2010) What Is COPD. http://www.nhlbi.nih.gov/health/dci/Diseases/Copd/Copd_WhatIs.html

[3] CDC (2010) COPD. http://www.cdc.gov/copd/index.htm

[4] EPA (2011) COPD.

http://cfpub.epa.gov/eroe/index.cfm?fuseaction=detail.viewPDF\&ch=49\&lShowInd=0\&subtop=381\&lv=list.listByCha pter\&r=235293

[5] Begley, C., Courtney, P. and Burau, K. (2011) Houston Hospitals Emergency Department Use Study. http://www.sph.uth.tmc.edu/uploadedFiles/Redesign_Website/Research/Research_Centers/Center_for_Health_Service s_Research/HSRC/Final2009BegleyMonday.pdf

[6] EPA (2011) COPD.

http://cfpub.epa.gov/eroe/index.cfm?fuseaction=detail.viewPDF\&ch=49\&lShowInd=0\&subtop=381\&lv=list.listByCha pter\&r=235293

[7] ESRI (2007) Evaluating Population Projections-The Importance of Accurate Forecasting. http://www.esri.com/library/whitepapers/pdfs/evaluating-population.pdf

[8] Anderson, W. (2005) Statistical Techniques for Validating Logistic Regression Models. Annals of Thoracic Surgery, 80, 1169.

[9] Merrill, R. (2008) Environmental Epidemiology: Principles and Methods. Jones \& Bartlett Learning.

[10] Sexton, K., Linder, S., Delclos, G., Stock, T., Abramson, S., Bondy, M., et al. (2005) A Closer Look at Air Pollution in Houston: Identifying Priority Health Risks. http://www.epa.gov/ttn/chief/conference/ei16/session6/bethel.pdf

[11] Koerber, K. (2006) Migration Patterns and Mover Characteristics from the 2005 ACS Gulf Coast Area Special Products. http://www.census.gov/newsroom/emergencies/additional/gulf_migration.html

[12] Gershon, A., Wang, C., Wilton, A., Raut, R. and To, T. (2010) Trends in Chronic Obstructive Pulmonary Disease Prevalence, Incidence, and Mortality in Ontario, Canada, 1996 to 2007. Archives of Internal Medicine, 170, 560-565. http://dx.doi.org/10.1001/archinternmed.2010.17

[13] London, S. (2011) COPD Exacerbations Twice as Common in Winter.

[14] Wedzicha, J.A. (2004) Role of Viruses in Exacerbations of Chronic Obstructive Pulmonary Disease. Proceedings of the American Thoracic Society, 1, 115-120. http://dx.doi.org/10.1513/pats.2306030

[15] Turpin, B., Clifford, P., Morandi, M., Colome, S., Stock, T., Eisenreich, S., et al. (2007) Relationships of Indoor, Outdoor, and Personal Air (RIOPA): Part II. Analyses of Concentrations of Particulate Matter Species. Research Report (Health Effects Institute), No. 130, 1-77.

[16] LUNGUSA (2010) African Americans. http://www.lungusa.org/stop-smoking/about-smoking/facts-figures/african-americans-and-tobacco.html

[17] CDC (2012) Eliminate Disparities in Cardiovascular Disease (CVD).

[18] Mensah, G. and Brown, D. (2007) An Overview of Cardiovascular Disease Burden in the United States. Health Affairs, 26, 38-48. http://content.healthaffairs.org/content/26/1/38.full 
Scientific Research Publishing (SCIRP) is one of the largest Open Access journal publishers. It is currently publishing more than 200 open access, online, peer-reviewed journals covering a wide range of academic disciplines. SCIRP serves the worldwide academic communities and contributes to the progress and application of science with its publication.

Other selected journals from SCIRP are listed as below. Submit your manuscript to us via either submit@scirp.org or Online Submission Portal.
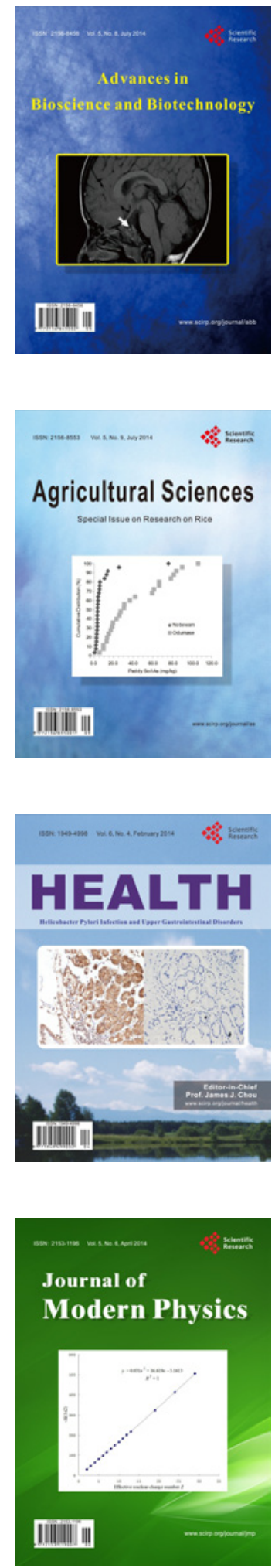
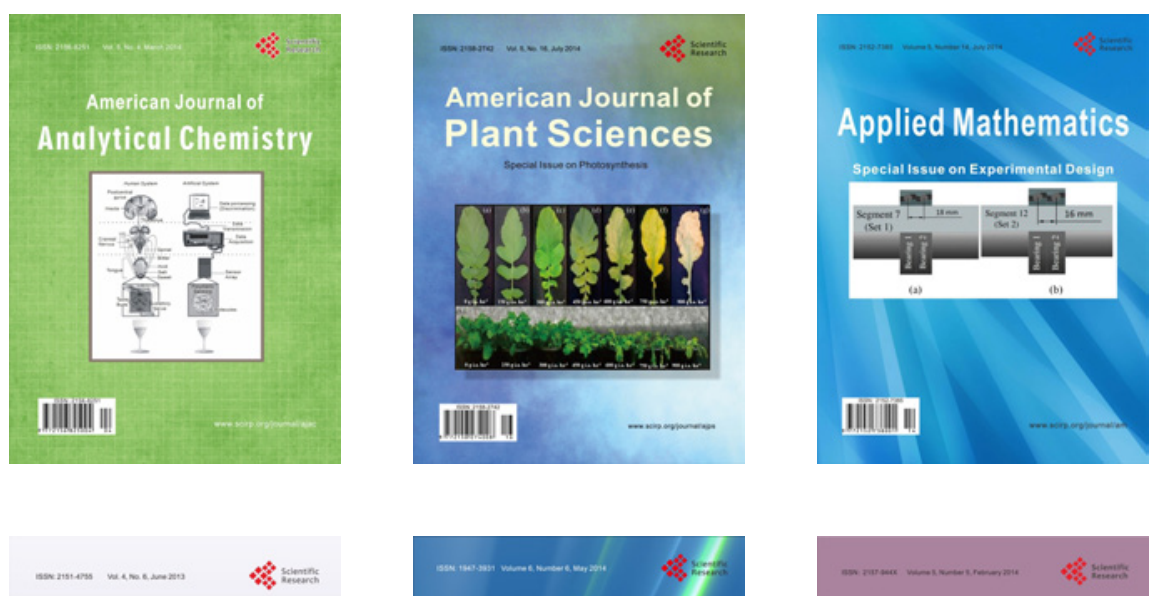

Creative Education
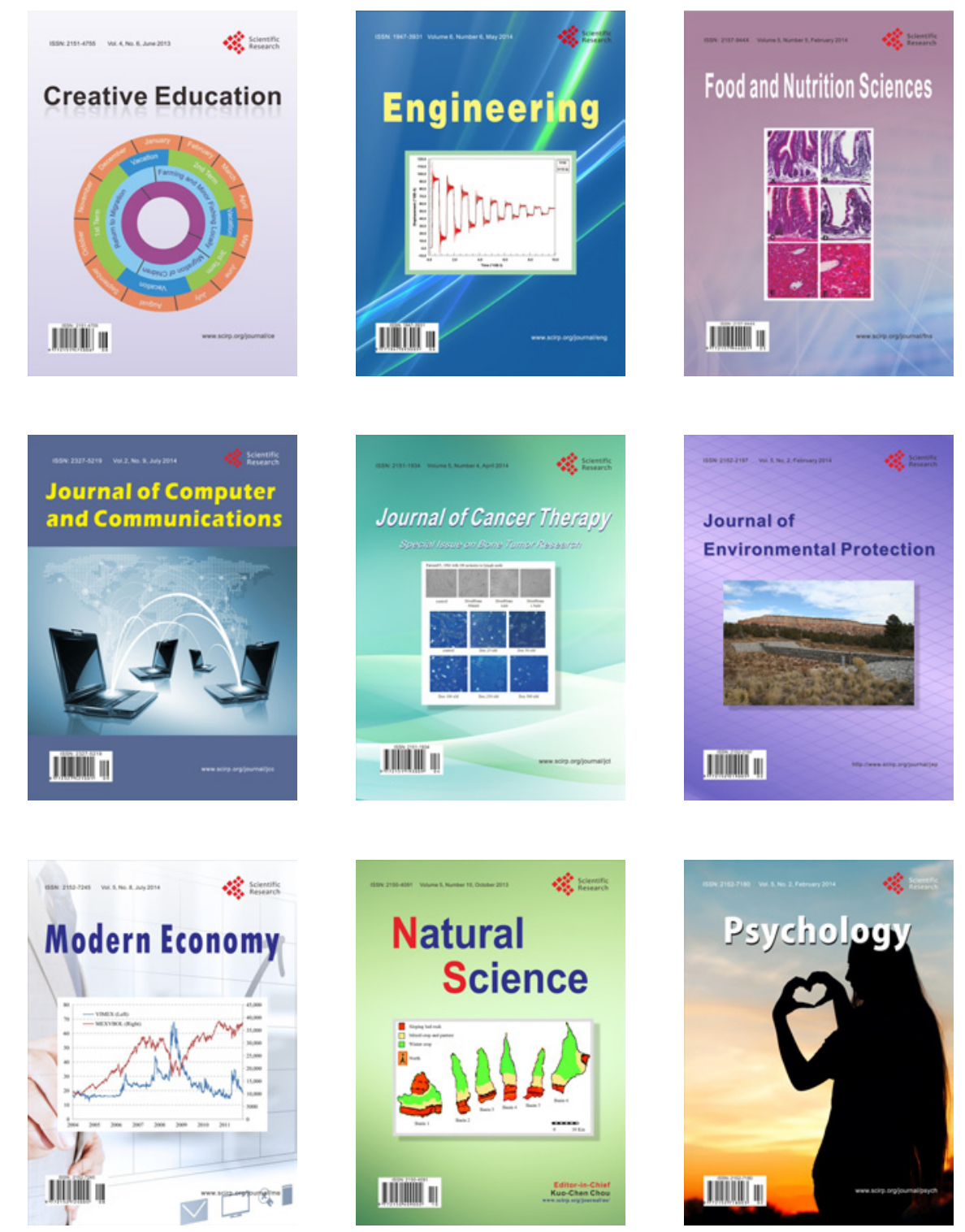